\title{
Languages as historical documents: the endangered archive in Laos
}

\author{
N. J. Enfield
}

\begin{abstract}
This paper reviews current discussion of the issue of just what is lost when a language dies. Special reference is made to the current situation in Laos, a country renowned for its considerable cultural and linguistic diversity. It focuses on the historical, anthropological and ecological knowledge that a language can encode, and the social and cultural consequences of the loss of such traditional knowledge when a language is no longer passed on. Finally, the article points out the paucity of studies and obstacles to field research on minority languages in Laos, which seriously hamper their documentation.
\end{abstract}

Keywords: languages; minorities; Laos

The existence of modern nations reflects a deep tendency in human nature for structuring social relations and maintaining social identity. As nation-builders know well, this intense sociality so remarkable in our species is effected by the most profound of our species-specific talents: language. Accordingly, most, if not all, nations have at least one official language. In the Lao PDR, that language is Lao, a SouthWestern Tai language also spoken in parts of Thailand and Cambodia. However, Laos is also home to speakers of languages other than Lao; it is surprising for some to learn that there are not one or two, not 10 or 20 , but some 80 or more different languages - in an area smaller than the UK. Laos is in fact the site of one of the highest degrees of linguistic diversity in the world, a fact that deserves to affect our view of the nation dramatically. ${ }^{1}$ Multilingual individuals commonly report that when speaking one language or the other, they are in a different world in

Daniel Nettle (1999), Linguistic Diversity, Oxford University Press, Oxford, p 153; see also Johanna Nichols (1991), Language Diversity in Time and Space, Chicago University Press, Chicago, IL. For an overview of Lao, see Enfield, N. J. (1999), 'Lao as a national language', in Evans, G., ed, Laos: Culture and Society, Silkworm Books, Chiang Mai, pp 258-290. 
terms of their manners, their patterns of thought and their mood. ${ }^{2}$ From this point of view, there are some 80 different 'worlds' in Laos, and only one is the official, promoted one. Two others - Hmong and Kmhmu - are promoted at the national level with radio broadcasting. In current portrayals of the nation of Laos, many dozens of local worlds are sidelined, if not entirely ignored. Further, most of them are critically endangered. ${ }^{3}$

\section{Overview of languages and language groups in Laos}

Most languages spoken in Laos belong to one of four language families. Hmong-Mien languages are spoken mainly in the country's northern provinces; these include varieties of Hmong and Mien spoken by descendants of recent migrations (ie within the last 200 years) from southern China. Other languages of this family are found in northern Thailand, northern Vietnam and south-western China. The Tai family of languages originated in the latter region. Tai languages are spoken throughout Laos, with Lao itself belonging to the South-Western branch; a number of minority languages of the same branch are spoken in the north (eg Black Tai and Thai Neua), particularly along the Vietnamese and Chinese borders. There are also small communities of speakers of languages of the Northern Tai subgroup, such as Sek, spoken in Khammouane. Outside of Laos, Tai languages are spoken in Thailand and areas of Cambodia, Vietnam, China, Burma and India. Languages of the Tibeto-Burman family are spoken in the far north of Laos, among mountain-dwelling minorities in provinces such as Oudomxay and Phongsaly; these languages include Akha, Phunoy and Lahu. Tibeto-Burman languages are also found in China, Thailand, Burma and the Himalayas. ${ }^{4}$

2 Wallace Chafe (2000), 'Loci of diversity and convergence in thought and language', in Martin Pütz and Marjolijn Verspoor, eds, Explorations in Linguistic Relativity, Benjamins, Amsterdam, pp 101-123. See also Edward Sapir (1949), Selected Writings, University of California Press, Berkeley, CA; Benjamin L. Whorf (1956), Language, Thought, and Reality, MIT Press, Cambridge, MA; John Gumperz and Stephen Levinson (1996), Rethinking Linguistic Relativity, Cambridge University Press, Cambridge; and Dedre Gentner and Susan Goldin-Meadow (2003), eds, Language in Mind: Advances in the Study of Language and Thought, MIT Press, Cambridge, MA.

3 Scholarly discussions of this issue on a global scale include David Crystal (2000), Language Death, Cambridge University Press, Cambridge; Daniel Nettle and Suzanne Romaine (2000), Vanishing Voices: The Extinction of the World's Languages, Oxford University Press, Oxford.

4 Enfield, N. J. (2005), 'Laos - language situation', in Brown, K., ed, Encyclopedia of Language and Linguistics, 2 ed, Cambridge University Press, Cambridge, pp 698-700. 
The language family represented most numerously in Laos is MonKhmer (Austro-Asiatic). Kmhmu belongs to the Northern branch of Mon-Khmer, and varieties of it are spoken across northern Laos, as well as in parts of northern Thailand and Vietnam. The central and southern provinces of Laos are home to dozens of languages of the Eastern branch of Mon-Khmer, with subgroups Vietic (eg Karì̀, spoken in Khammouane), Katuic (eg Katu, spoken in Sekong) and Bahnaric (eg Alak, spoken in Attapeu). (The fourth subgroup of Eastern Mon-Khmer is Khmeric, whose one member - Khmer - is spoken in Cambodia and Vietnam.) MonKhmer is a large and widespread language family, also represented in Cambodia, Malaysia, Burma, India, China, Thailand and Vietnam.

\section{Language endangerment}

One cause for urgency in linguistic research in Laos is language endangerment; of the languages mentioned in the previous paragraph, almost all are endangered. There has been an explosion of recent public discussion worldwide - with the publication of various books and the passing of various resolutions - of the ways in which languages are threatened and of what is lost when a language dies. ${ }^{5}$ Concrete steps taken to address the problem include the establishment of various funding bodies such as the Dokumentation Bedrohter Sprachen (DOBES) or Endangered Languages Documentation Project of the Volkswagen Foundation in Germany, the Hans Rausing Endangered Languages Project, and research projects such as the Endangered Languages Academic Programme of the School of Oriental and African Studies Department of Linguistics (London).

The world's languages are perishing fast, at an estimated rate of one every two weeks. ${ }^{6}$ Should anything be done? One view is that sociocultural change (and loss) is inevitable, that in most cases it is the speakers' own choice to stop using their language, and that they should be free to make this choice. Some say that language diversity is an inconvenience, but others oppose this view. ${ }^{7}$ There are essentially two

5 See Crystal, supra note 3, and Nettle and Romaine, supra note 3, as well as Nancy C. Dorian, ed (1989), Investigating Obsolescence: Studies in Language Contraction and Death, Cambridge University Press, Cambridge; and Lenore A. Grenoble and Lindsay J. Whaley, eds (1998), Endangered Languages: Current Issues and Future Prospects, Cambridge University Press, Cambridge.

6 Crystal, supra note 3, at p 19.

7 Nettle and Romaine, supra note 3, at p 19 discuss Rupert Murdoch's avowed monolingualist position. 
positions in favour of doing something about language endangerment. The first advocates protecting the endangered language, arguing that the causes of language loss are found in large-scale and corporate abuse and unfair exploitation of power and resources. The typical scenario is that an economically disadvantaged group will view its own language and culture as holding it back socially and economically, and will abandon the language in order to move into the majority identity, and enjoy its promised advantages. Daniel Nettle and Suzanne Romaine argue that if the socioeconomic inequalities at the root of this process were corrected in the first place, minority people would have more control over their lives and livelihoods, and would not be driven to abandon their own languages in the shift to using majority languages. Nobody questions the wisdom of learning and using another language, especially when it is the language of one's more powerful neighbours and compatriots, but adopting a new language does not entail abandoning one's own. The complicated and politically charged issues that arise here are beyond the scope of the present discussion. ${ }^{8}$

The second position in favour of action on language endangerment is that, irrespective of whether teetering languages should be left to tip and fall, they must be properly documented while they are still actively spoken. This is above all in the interest of the speech community and their later generations. It often happens that a community will lose its language in a socially 'upward' move, and then later (some generations later) - when conditions improve, the socioeconomic pressures have eased, and cultural identity becomes a genuine choice - they come to regret this loss. Without good quality documentation while the language is vital, these later generations have no hope of reviving a language once it is moribund or dead.

\section{Languages as archives}

I want to consider more closely a second reason why languages ought to be properly documented before they perish. Languages are archives of a great deal of information of interest to many, if not all, disciplines of human science, as well as other branches of science such as agriculture, biology and medicine. Archives worldwide are endangered; when they are lost, they cannot be replaced. This is true not only for books, films and manuscripts, but for the very languages in which these are

$8 \quad$ Nettle and Romaine, supra note 3, Ch 7; see also Crystal, supra note 3. 
produced. Different storage media have radically different properties compare the respective shelf life and modes of access of stone tablets, palm-leaf manuscripts, paper and living people. The living person seldom lasts a hundred years, and furthermore presents a wide range of access problems to the scientist (if the person is busy, disinterested, drunk, etc). For this and many other reasons, documenting comprehensive information about linguistic structure is a significant undertaking.

Consider what it is that the descriptive linguist is trying to find out when he or she describes a language. What do these linguistic archives contain? One thing they yield is knowledge of use to science: indigenous categorization of wildlife, plant life, environmental cycles and so on. Such information has applications in medicine, agriculture and conservation, and is of significant value to work in social development. While it may be argued that this kind of information is in some cases not actually encoded in the language itself, it is known that when a community switches to a new language, ethnoscientific knowledge ceases to be passed on to younger generations. ${ }^{9}$ The processes that cause people to abandon their language are the same ones that cause them to stop making the conceptual distinctions their former language reflected. In Laos, this is significant due to the especially high degree of biodiversity in the nation's natural environment. Many inhabitants have a close relationship with the environment by virtue of their daily livelihood; the ecological knowledge and expertise of ethnic minorities are to a great degree encoded in their languages, and to a large extent they are possessed only by speakers of specific languages. Linguistic and ethnographic fieldwork is a prerequisite for documenting and disseminating that knowledge.

\section{Language and world view}

I now concentrate on a second type of information contained in these archives: information about the way in which speakers of the language share a view of the world. This can be inferred by viewing language as a set of conventions that enable speakers to solve problems of coordination in daily life. For example, getting someone to pass the salt is greatly assisted by having a word for 'salt' in the language. Less mundanely, the words and grammatical constructions of a language allow its speakers to attend to, and communicate very effectively with regard to, certain features of the things they want to talk about. These are the

$9 \quad$ Nettle and Romaine, supra note 3. 
things they habitually talk about. In order to understand how this works, we first need to ask how a language acquires its structure in the first place. Compare the notions of 'a language' and 'a nation'. A nation in the sense of, say, the Lao nation, partly has a natural existence, but is partly, if not mostly, constructed deliberately, with a particular outcome in mind, and with a great deal of conscious human effort. That is, there has been and continues to be much reflection and explicit attention-drawing by those in power to the existence of the nation and to its properties, such as an idealized shared world view defined both positively (in terms of what the nation is) and negatively (in terms of what it is not).$^{10}$ The target idea is that a geographically determined group of people (citizens) collectively hold a particular set of views and practices.

Turning nations and national languages into reality is a matter of intentionally establishing a culture, achieved by means of what one could call a 'visible hand'. At a deeper level of history - at the timedepth for which we have had language as a species, ie over many tens of thousands of years - an invisible hand is at work quietly constructing something much more enduring: a language. ${ }^{11}$ This process involves a public discourse, but unlike the state-inspired one, it is not conducted with a particular outcome in mind. Here is how it works. Linguistic items such as words are in principle one of the basic units of linguistic processes. A linguistic element such as a word is a solution to a coordination problem that is recurrent in a given speech community. The Kmhmu word prcaan - meaning 'to try to stand firm by pressing one's foot against something' (climbing up a slippery path, for example) would not exist if Kmhmu speakers had not regularly traversed steep slippery paths (or, more precisely, had not regularly talked about such traversals) for the last several centuries. ${ }^{12}$ Speakers of Karì̀, a Vietic

10 Grant Evans (1997), The Politics of Ritual and Remembrance, Silkworm Books, Chiang Mai.

11 Adam Smith coined the term 'invisible hand' to refer to the mechanism by which macro-level patterns in an economy emerge not from the intentions of any individual, but from the aggregate of micro-level intentions. Adam Smith (1904, originally published in 1776), An Inquiry into the Nature and Causes of the Wealth of Nations, Methuen, London. For example, queues at a supermarket will tend to be each around the same length, although the individuals in line do not intend that to be the case, but rather merely go to the queue that currently appears to be shorter than the rest in order to minimize their own waiting time. For examples and discussion, see Thomas C. Schelling (1978), Micromotives and Macrobehavior, W. W. Norton, New York.

12 Suksavang Simana, Somseng Sayavong and Elizabeth Preisig (1994), Kmhmu'-LaoFrench-English Dictionary, Institute for Cultural Research, Ministry of Information and Culture, Vientiane, p 276. 
language of Khammouane, would not have a word pa'ùùt ('to keep bees at bay with a smoking torch while scaling a tree to retrieve honey') if their ancestors had not collected honey from the local forests regularly for the last several centuries.

These words exist because they are useful. Each idiomatic expression is a short cut, an abbreviated reference that leaves out a great deal of information, but which nevertheless is enough to get the job done. Consider what is meant in Lao by the expression fang thêe $t$, literally 'listen (to a) sermon'. While the expression explicitly refers only to the key components of 'listening' and 'sermon', the meaning it conveys is far more specific: the participants are dressed in a certain way and seated in a certain way; they are at a temple, they are rightfully participating in an act of religious devotion; the time and date of the event are within certain constraints, and so on. ${ }^{13}$

\section{Linguistic shortcuts and community coherence}

The expression fang thêêt is a communicative short cut that Lao speakers take, a short cut made possible due to the high degree of conventionality of social activities such as 'listening to a sermon'. The principle also applies to more mundane situations. For example, the Karì̀ expression saaw krnoo' means 'to go up (into a) house'. This apparently simple expression carries with it a great deal of cultural importance, in the context of a set of beliefs and practices concerning taboo-like restrictions on certain people ascending to certain houses at certain times. (For instance, during menstruation, women are forbidden to ascend any house.) As a first-time visitor in Karì̀-speaking villages, I was advised to ask when approaching a house and before climbing up to enter it, 'saaw krnoo' tôô kii dêêh?' (Can I ascend the house?) - this is in order to avoid the negative consequences of transgressing a temporary proscription on ascending. The expression saaw krnoo', 'ascend house', has richer meaning than its literal translation suggests. Another example from Karì̀ is 'an plìc, literally 'to eat chilli pepper'. In Karì̀ society, as in other societies of Laos, it is normal to greet people at certain times of day with a question 'What have you eaten (for breakfast/dinner)?' The common answer ' an plic' says more than simply that I ate chilli pepper with my staple (rice, corn or cassava,

13 Enfield, N. J., ed (2002), 'Cultural logic and syntactic productivity: associated posture constructions in Lao', Ethnosyntax: Explorations in Culture and Grammar, Oxford University Press, Oxford, pp 231-258. 
depending on the season); it says that I did so because I was unable to find anything more substantial (usually fish) to eat.

The simple expression, then, is a short cut to a richer interpretation. The more time you spend with certain people, the more information you share with them, and the more short cuts you can take. In turn, the more short cuts your communication system makes, the more you are required to rely on shared information, the easier it is just to talk to your regular social associates, and so on. ${ }^{14}$ This contributes to a centripetal force in communities, pushing members of social groups towards each other. The centripetal force due to members' habitual close social association leads to a bundling of social conventions. That is, while each linguistic item (such as a word) is a detachable and independent convention, each language is a very large bundle of such items. ${ }^{15}$ Languages are more than mere bundles, however. It is technically possible that linguistic items could be randomly distributed across populations, but they are not. The notion of 'languages', ie that a particular bundle of signs is identifiable and consistent across populations, reflects this. Further, the internal structure of languages is far from bundle-like, with tightly cohering constituent items and subsystems - lexical items, morphological patterns and grammatical constructions. ${ }^{16}$

Current work in evolutionary anthropology hypothesizes as to the adaptational mechanisms behind having linguistic differences across communities. These provide an unbluffable badge of community membership: speaking as a native in a certain dialect (ie with a certain accent, or using certain key words and grammatical constructions) is a sign of having committed a major portion of one's formative years to living in a certain community. ${ }^{17}$ One example is the subtle but pervasive difference in the quality of vowels between Lao as spoken by natives of Vientiane and the speech of Phutai speakers in Bolikhamsai, Khammouan and Savannakhet provinces of Laos. (This is reflected in jokes such as the Phuthai speaker who reports that his wife's bicycle - lot mia - has

14 Enfield, N. J. (2006), 'Social consequences of common ground', in Enfield, N. J., and Levinson, S. C., eds, Roots of Human Sociality: Cognition, Culture, and Interaction, Berg, London, pp 399-430.

15 Nettle, supra note 1.

16 William Croft (2000), Explaining Language Change: An Evolutionary Approach, Longman, Harlow.

17 Nettle, supra note 1, and Robin Dunbar (1999), 'Culture, honesty, and the freerider problem', in Robin Dunbar, Chris Knight and Camilla Power, eds, The Evolution of Culture, Rutgers University Press, New Brunswick, NJ, pp 194-213. 
been stolen, and because of his pronunciation of $i a$ as $\hat{e} \hat{e}$, is misunderstood to be reporting the theft of his bus - lot mêe.)

The mechanism whereby such fine distinctions (which are hard to learn and even harder to unlearn) are a genuine signal of commitment to a particular community in one's formative years is said to serve as a preventative of the free-rider problem, ie the danger that an individual will take resources from the social group without paying them back and then simply move on to another group. ${ }^{18}$ Speaking a language natively is taken to be irrefutable proof of community membership, and of historical continuity of transmission through generations of conventions within an identifiable community. In Laos, not only are there many dozens of distinct language communities (eg Lao, Kmhmu, Hmong, Brou), there are many further dozens of communities distinguished by dialect differences (eg between varieties of Lao spoken in Luang Prabang, Vientiane and Pakse; varieties of Brou spoken in Khammouane, Savannakhet and Salavane; or varieties of Lahu/Musoe spoken in Phongsaly and Luang Namtha). From this perspective, the dozens of 'language worlds' turn into hundreds.

\section{Historical linguistics}

The issues discussed in previous paragraphs concerning the social and ethnographic relevance of language and the relevance of micro-level social processes have come to inform research on historical linguistics. The process of language change is now better understood. A traditional assumption has been that a language, like a species of organism, shows historical continuity, in which each specimen is a contained organic system. Languages do not evolve by descent and modification at the level of the whole language itself, however; if anything in language evolves in this way, it is each individual linguistic item, eg a word. ${ }^{19}$ Words and other linguistic items are individual memes, ideas that

18 See Nettle, supra note 1; Dunbar, supra note 17; and Robin Dunbar (1996), Grooming, Gossip and the Evolution of Language, Faber and Faber, London, and the references therein.

19 Croft, supra note 16; Enfield, N. J. (2003), Linguistic Epidemiology: Semantics and Grammar of Language Contact in Mainland Southeast Asia, RoutledgeCurzon, London; Enfield, N. J. (2005), 'Areal linguistics and mainland Southeast Asia', Annual Review of Anthropology, Vol 34, pp 181-206. See also Sarah Grey Thomason and Terrence Kaufman (1988), Language Contact, Creolization, and Genetic Linguistics, University of California Press, Berkeley, CA; and Rudi Keller (1994), On Language Change: The Invisible Hand in Language, Routledge, London/New York. 
replicate through a population of minds, each with their own unique career. The history of each individual word is not the history of the whole language, but historical linguists point out that languages can nevertheless often be treated as if they were historically whole entities, as long as their mode of transmission is normal. ${ }^{20}$ This means that if the communities that speak these languages are not subject to radical upheaval (eg by division and/or relocation due to war, slavery, etc), then more or less the full bundle of items will be passed on to children, and the language as a whole is replicated in their children's speech and through into adulthood.

If a language exists, therefore, this means that there has been, for some (very long) period, a centripetal force on communicative convention within the historical community speaking the language; this is one sense in which a language is a historical document. In this sense, it is not the content of the linguistic structures that matters, but their distribution across populations. For example, the South-Western Tai languages can be divided into two groups, depending on whether a series of words are pronounced with an aspirated sound (eg $p h, t h, k h)$ or an unaspirated sound (eg $p, t, k$ ). Based on this division, Lao is a 'PH' language (with phii 'fat', thaang 'way', khan 'handle'), while Tai Neua is a 'P' language ( $p i$ 'fat', taang 'way', kan 'handle'). This kind of information has led to concrete hypotheses about the relatedness between various languages of Laos, including their major groupings (Tai, Tibeto-Burman, Mon-Khmer, Hmong-Mien, Sinitic) and subgroupings (eg Eastern Mon-Khmer languages of southern Laos versus Northern Mon-Khmer languages of northern Laos, Northern Tai languages such as Sek versus South-Western Tai languages such as Lao and Phuthai; within South-Western Tai, 'P' languages such as Lue and Thai Neua versus 'PH' languages such as Lao). ${ }^{21}$

20 Thomason and Kaufman, supra note 19; on the broader evolutionary perspective, see Richard Dawkins (1976), The Selfish Gene, Oxford University Press, Oxford; and Robert Aunger, ed (2000), Darwinizing Culture, Cambridge University Press, Cambridge.

21 See, inter alia, William J. Gedney (1989), Selected Papers on Comparative Tai Studies, University of Michigan Press, Ann Arbor, MI; Jerold A. Edmondson and David B. Solnit, eds (1988), Comparative Kadai: Linguistic Studies beyond Tai, Summer Institute of Linguistics and University of Texas Press, Arlington, TX; Jerold A. Edmondson and David B. Solnit, eds (1997), Comparative Kadai: The Tai Branch, Summer Institute of Linguistics and University of Texas Press, Arlington, TX; and Luo Yongxian (1997), The Subgroup Structure of the Tai Languages: A HistoricalComparative Study, University of California Press, Berkeley, CA. 


\section{Cultural/historical content of linguistic conventions}

Beyond the form and distribution of linguistic conventions across the geographic area of Laos, there is another and perhaps more important point, already alluded to above, regarding the historical establishment of community-wide linguistic convention. This concerns the content of those conventions. Languages are structured by people in real-time communicative situations; words, idioms and grammatical structures arise from here-and-now solutions of speakers to coordination problems in face-to-face interaction. They are brought to full membership in the language when sociometric processes of innovation diffusion bring them to conventional status. ${ }^{22}$ Each language, each treasury of community-specific communicative conventions, is an archive of historical solutions to problems of social coordination. In the history of humankind, each unique accidental experiment in which a community has established a set of many thousands of solutions to recurrent communication problems has resulted in a unique multipurpose tool for the job: a local language.

Roger Brown wrote that 'the categorical structure of the native language is the key to the entire culture'. A language is one of the richest sources of ethnographic information about its speakers. ${ }^{23}$ Like any other language, Lao is replete with examples. Words like sabaaj, 'happy, comfortable, easy, well'; kêng, 'capable, clever'; muan, 'fun, enjoyable, exciting'; ngaam, 'nice, beautiful, good-looking'; bò pên ñang, 'no problem'; aaj, 'shy, ashamed, embarrassed'; baan, 'village, home'; paphêênii, 'cultural tradition'; pa-daek, 'jugged fish'; van sin, 'holy day'; lok kaa, 'pull up rice seedlings (for replanting)'; kin law, 'drink liquor'; kuu/mùng, 'I/you' (non-respect); and thaan/khaaphacaw, 'I/ you' (high respect) are not directly translatable into English; nor are they explicable without a great deal of ethnographic background. Properly understanding these and most other words of Lao entails knowing the culture of the language's speakers. The same goes for the country's minority languages, each of which similarly encodes a vast ethnographic background, a massive set of distinctions that constitutes the very definition of a culture. This is what is irretrievably lost when a language dies.

22 Enfield, supra note 19 (both works).

23 Sapir, supra note 2; Anna Wierzbicka (1992), Semantics, Culture, and Cognition, Oxford University Press, New York. The quotation is from Roger Brown (1958), Words and Things, The Free Press, Glencoe, IL, p 20. 
In sum, then, a language is a historical document in more ways than one. First, documentation of a language today will be invaluable to historians of the future. Second, in its state at any given moment, a language can provide for inferences about historical relationships between groups of people, from hypotheses of regular change due to descent-by-modification (causing languages to become less alike) and evidence of borrowing (causing languages to become more alike). These inferences are based on the presence or absence of historically related words in different languages, and their current phonological shape - ie the way they sound. For instance, the word in Lao for 'betel' is phuu, while in Thai it is phluu, and in Thai Neua it is $p u$. This is the kind of evidence contributing to the hypothesis that Lao and Thai are more closely related historically than either is to Thai Neua. Historically, this means that linguistic ancestors of Thai and Lao speakers formed a single speech community more recently than they did with those of Thai Neua speakers. Third, the meanings encoded in the words and grammar of a language can reveal the concepts for which a community has historically developed shorthand for face-to-face interaction. This reveals further information about speakers' history, concerning livelihood, technology, social organization and other aspects of culture. The timescale involved in the emergence of a language's structure is much greater than that of the discourse of the modern nation of Laos (scarcely a hundred years). The processes involved have been instigated and conducted 'invisibly' by individuals at ground level, not from the top down by very visible nation-builders.

\section{Attitudes to languages and their diversity}

Lay people often have strong views about language, whether they concern the status of dialects or varieties of their own language, or that of other languages that they may or may not understand. A common view is that a certain language or dialect is 'backward', meaning that it is less developed, less rich in structure, less expressive, or not even a proper language at all. This view aligns with an appraisal of the language in question as socially low (whether the viewpoint is from 'above' or from the 'low' position of the speech community itself). Languages spoken in Laos inhabit different positions on a kind of 'backwardness hierarchy', and each language's position is relative. Lao itself is considered by many as underdeveloped in comparison with international languages such as English, as well as more highly standardized lan- 
guages such as neighbouring Thai. For example, there is little technical or industrial reference material available in the Lao language. For such resources, it is possible in urban Laos to obtain a rich array of advanced textbooks, guides and technical manuals written in languages other than Lao (eg English, Thai, French or Russian). These foreign languages are a prerequisite for training in technical and professional occupations, yet Lao remains the national standard language. ${ }^{24}$

By contrast, Lao appears highly developed when compared with the country's ethnic minority languages, few of which have written forms or are used in formal education or public broadcasting. Minority languages of Laos lack most, if not all, of the defining properties of standard languages, such as use in education, broadcasting or publishing. ${ }^{25}$ Some minority languages are less 'backward' than others, however, being more widely spoken and showing some degree of standardization. Speakers of Hmong, for example, maintain a vibrant tradition of literacy (using a Roman-based script), and are increasingly using the written language in public settings such as the commercial world, in radio broadcasting and in other public uses of language such as promotion of rural development and health programmes. The Roman-based orthography in popular use is unofficial, as the government stipulates that minority languages should be written in the Lao script, but nevertheless this unofficial script is being used in semi-official contexts. The situation with Kmhmu is similar.

These are by far the most populous of the minority languages of Laos, however. A few others serve as local lingua francas for different minority groups who are in regular contact; in these cases, one minority language becomes dominant. For example, the Katuic language Ngkriang (also known as Ngèq) is a common language for communication between people of a number of different minorities living in Kalum district, Sekong. Other cases are the Katuic language Brou in the central and eastern parts of Khammouan, the Bahnaric language Tariang in Dakchung district of Sekong, and the Tibeto-Burman language Phunoi in Phongsaly. There are many more such examples; language contact and the discourse of sociolinguistic relations within minority language communities in Laos are major topics for research.

24 See Enfield, supra note 1.

25 See Anthony Diller (1991), 'What makes Central Thai a national language?' in Craig J. Reynolds, ed, National Identity and Its Defenders: Thailand, 1939-1989, Silkworm Books, Chiang Mai, pp 87-131. 


\section{Minority language policy}

Ordinary people's attitudes to language often differ considerably from official opinions expressed by the authorities. The Lao government has long professed support for minority languages, in the present era as well as throughout the period of revolutionary struggle. Official government policy states that ethnic minority children have a right to education in their first language. A relevant section of the 'Resolution of the Party Central Organization Concerning Ethnic Minority Affairs in the New Era' (1992, signed by Kaysone Phomvihan) is summarized as follows:

'The network of formal primary education should be expanded to guarantee that all children of school age attend school. In addition, the policy calls for a revival of the "ethnic youth" schools in mountainous areas, which were in place in liberated zones during the war, with the condition that quality should be emphasized. It is also emphasized that minority children have the same rights to education as other children in the lowlands and cities. A detailed plan for teacher training is called for, directed at the ethnic minorities in remote areas, together with a policy and the personnel for its realization. Here, most importantly, the mandate is given for the relevant organization to urgently research the writing systems of the Hmong and the Khmou using the Lao alphabet as was formerly used in the old liberated zones for use in areas occupied by these ethnic minorities, to be studied together with the Lao language and alphabet. ${ }^{26}$

Orthography is the issue of greatest symbolic value. It is officially not allowed for a minority language to use an orthography based on anything other than the Lao script, which belongs to the standard language. ${ }^{27}$ The section of Ethnic Minority Affairs resolution cited above specifically names Hmong and Kmhmu, the most populous ethnic minorities; Lao-based orthographies for these two languages were developed in areas of the Liberated Zone of upland Laos between the period of French

26 International Labour Organization (2000), Policy Study on Ethnic Minority Issues in Rural Development. Project to Promote ILO Policy on Indigenous and Tribal Peoples, International Labour Office, Geneva. Evans, supra note 10, discusses various aspects of minority policy.

27 Enfield, supra note 1, and N. J. Enfield and Grant Evans (2000), 'Transcription as standardisation: the problem of Tai languages', Proceedings of the International Conference on Tai Studies, July 29-31, 1998, Mahidol University Institute of Language and Culture for Rural Development, Bangkok, pp 201-212. 
administration and the establishment of the Lao PDR. However, these scripts were put to limited use, for example in disseminating political pamphlets and for some administrative purposes. It is unlikely that the degree of literacy was high, and it may be that the function of these literacy programmes was essentially symbolic. It is unknown whether languages other than the two larger minority languages were given support of this kind.

While both Hmong and Kmhmu have official orthographic representation in Lao script, then, neither of these scripts is in regular use within communities speaking these languages. This is not because the communities are not literate, at least in the case of Hmong. Hmong speakers widely employ a Roman orthography, and apparently never use the official Laobased one. People write the language in personal and business correspondence (especially between Hmong communities of Laos and those in the USA), as well as on signs and notices in the marketplace and on merchandise (eg Hmong music CDs). Despite these uses of a non-Lao script being officially not allowed, I have not heard of any Hmong speaker being arrested for this. Kmhmu is less actively used in written form; in some Kmhmu language publications, Lao- and Roman-based orthographies appear side by side. ${ }^{28}$ These publications are, however, of an academic and technical nature, and are not widely accessed by Kmhmu speakers.

Despite the Lao government's official position of support for minority languages (which includes basic research), there is little genuine demonstration of commitment to such a position. Currently available reference sources on minority languages such as Kmhmu, Katu, Phunoi, Jru' and Nyaheun are the product of dedicated scholars who have had to struggle to find ways to conduct their research and have often been considerably restricted in this endeavour - despite government involvement in a number of these projects. ${ }^{29}$ This is - perhaps surprisingly,

28 Suksavang et al, supra note 12, and Suksavang Simana and Elizabeth Preisig (1999), Kmhmu' Language Lessons (trial edition), Vientiane.

29 See the two sources cited in the previous footnote, as well as Jan-Olof Svantesson, Damrong Thayanin and Kristina Lindell (1994), Kammu-Lao Dictionary (in Lao), Ministry of Information and Culture, Vientiane; Nancy Costello and Institute of Research on Lao Culture and Society (1993), Katu Folktales and Society, Ministry of Information and Culture, Vientiane; Pamela Sue Wright (2003), 'Singsali (Phunoi) speech varieties of Phongsali province', Language and Life Journal, Vol 1, pp 6273; Pascale Jacq (2002), 'A description of Jruq (Loven): a Mon-Khmer language of the Lao P.D.R.', Master of Philosophy thesis, Australian National University (to be published as A Description of Jru'(Loven), Mon-Khmer Studies Special Publication, Mahidol University, Bangkok); and Pascale Jacq and Paul Sidwell (forthcoming), Sketch Grammar of Nyaheun, a West Bahnaric Language. 
given the Lao government's close political ties to Vietnam - in contrast to the Vietnamese government's serious attention to supporting its minority languages, in a linguistic setting similar to that of Laos. Vietnam's Ministry of Education has produced publications and orthographic primers for primary education in some half-dozen minority languages. The Lao government has not followed this lead, and instead has failed to take the task of minority language education seriously. It is not clear why. During the late 1990s, a major national aid project on 'Education for Minority Girls' was launched. There were long deliberations on policy and implementation, which led from an original possibility of developing primary curriculum materials in minority languages, to a watered-down commitment to developing Lao-language materials tailored to the needs of specific language groups, and finally to a complete abandonment of the whole idea of accommodating minority languages into the curriculum at all. The result is that a single set of Lao-language materials was designed for teaching literacy to minority children across the entire country.

A major part of the problem is that so little is known about the country's minority languages. Not only are there no dictionaries, grammars or other reference sources for most of them, it is not even clear approximately how many there are, where they are spoken, by whom and in what kinds of social contexts. Information about language distribution has generally not been gathered using even the most basic technical linguistic methods. If you want to know which languages are spoken in a place, it is not enough to ask the locals 'What language do people speak here?' If you ask this question in, say, a village of the upper Nam Theun area of Khammouan, you could get one of four answers: 'Brou language', 'Sô language', 'Makong language' or 'Lao Theung language'. These are all used to designate one and the same Katuic language (referred to by its own speakers as Brou). The different names are appropriate in different situations - depending on, for example, whether one is talking to a government official, a lowland Lao speaker or a local from the next valley.

Moreover, not only do multiple names for some minority languages co-exist, so do multiple names for the ethnic groups that speak them. Distinctly named ethnic groups might speak the same language; for example, the Makong of Khammouan and the Katang of Salavane both speak dialects of Brou. Furthermore, official lists of languages and ethnic groups recognized by the government have changed from time to time, with 49 and 68 being memorable numbers. Again, it is not clear whether 
these estimates are based on empirical criteria. ${ }^{30}$ Official figures on ethnic minorities have been given in absolute numbers rather than as lists that supply information such as names of the individual groups, population, location, criteria for categorization, etc. The fluid and mysterious nature of the Lao government's official assessments of ethnic and linguistic diversity accords with our general ignorance of the facts, and underlines the need for primary empirical research.

A common obstacle to linguistic and ethnographic documentation across the board is lack of funding, and this is part of the problem for scholars with plans to conduct research in Laos. Even with both willingness and sufficient funding, would-be researchers of endangered minority languages are frustrated by Lao authorities' consistent discouragement of primary fieldwork and other academic activity concerning those languages. As an example, consider the attempt in 2003 by a group of social researchers and development workers to hold a 'Symposium on Minority Language Education'. The issue for discussion was that of using minority languages in primary education. As stated above, the Lao government has an official policy stating that minority languages should have writing systems and should be used in primary education. This is a sensible policy for a number of reasons, including (a) the country's massive linguistic diversity, (b) the well documented problems of teaching literacy to children using a language they do not yet understand, (c) the well documented benefits of teaching literacy to children using a language they do understand, and (d) the considerable social advantages, at both local and national levels, of providing institutional support to minority languages and their speakers. However, despite the existence of this official policy, there is in reality no official first-language education for minority children in Laos - although it is well known that minority languages are used in the primary school classroom, through necessity.

The single aim of the proposed Symposium on Minority Language Education was to raise these issues for public discussion, with invited contributions from government officials, development workers, academics and other consultants. The proposal received funding support and the organizers went ahead with arrangements, but the symposium was cancelled by the authorities at the last minute, with no clear explanation. This debacle is reminiscent of the frustrations many individual

30 See Lao Front for National Construction (2005), The Ethnics [sic] Groups in Lao $P D R$, Lao Front for National Construction, Vientiane. 
researchers have experienced in trying to conduct research projects in Laos. Scholars who have submitted proposals have waited literally years for official permission to undertake field research. Long delays as well as rejections of research proposals have occurred without a coherent explanation. It is difficult to comprehend this resistance to field research, given that willing researchers are proposing not only to collect and disseminate valuable primary data, but to provide funding and training for the activities of native Lao researchers.

\section{Conclusion}

The linguistic diversity found in Laos is of special scientific importance. Language is a key part of what it is to be human. As with other species, human infants are born in essentially the same initial state, but unlike other species, humans acquire, in the communities in which they are raised, radically different conventions of adult behaviour. Language is central to this, and is itself a prime example of community-specific behavioural convention. How diverse is human social and intellectual life? Are there concepts that deserve shorthand for communication in all societies? There are few serious candidates for semantic universals, which means that many, if not most, concepts encoded in a language may be unique to that language, and therefore of intrinsic ethnographic and historical interest. ${ }^{31}$ Globally, the results of more than 5,000 experiments in community structuration of the conceptual world are waiting to be assessed, but they are perishing much faster than we can get to them. As a site of nearly the highest degree of linguistic diversity in the world, Laos deserves urgent attention.

31 Cliff Goddard (2001), 'Lexico-semantic universals: a critical overview', Linguistic Typology, Vol 5, pp 1-65. 